\title{
La Zona Metropolitana de Querétaro en proceso de metropolización: 1990-2010.
}

Queretaro’s Metropolitan Area in metropolization process: 1990-2010.

Recibido: diciembre 2019

Rubí del Rocío Vázquez Cruz ${ }^{1}$

Aceptado: marzo 2020

\section{Resumen}

En las zonas metropolitanas de México los efectos del proceso de metropolización han generado un crecimiento urbano de tipo disperso. Se conoce que este fenómeno emerge en el contexto de la globalización, como un proceso socioeconómico que se manifiesta físicamente en el territorio y produce transformaciones urbanas, ambientales, económicas, sociales, políticas y culturales en las ciudades. Aplicando el enfoque de análisis territorial, el estudio aborda el proceso de metropolización en la Zona Metropolitana de Querétaro, la cual ha destacado por lo acelerado que se ha expandido en su superficie de urbanización. En este caso, la metodología muestra la expansion secuencial de la urbanización en un territorio de escala metropolitana y como puede explorarse comparativamente entre las décadas 1990-2010.

\section{Palabras Clave:}

análisis territorial; proceso de metropolización; crecimiento urbano.

\begin{abstract}
The effects of the metropolization process in the metropolitan areas of Mexico have generated a disperse type of urban sprawl. It's known that this phenomena flourishes in the globalization context, as a socioeconomic process that manifests physically in the territory and produces urban, environmental, economic, social, politic and cultural transformations in cities. Applying the territorial analysis approach, the study focuses on the metropolization process in Queretaro's Metropolitan Area, which has been noted for the accelerated sprawl on its urban surface. In this case, the methodology shows the urbanization sequential expansion in a metropolitan scale territory, and how to make a comparative exploration between decades 1990-2010.
\end{abstract}

\section{Keywords:}

territorial analysis; metropolization process; urban sprawl.

\footnotetext{
${ }^{1}$ Nacionalidad: mexicana; Doctora en Arquitectura; adscripción: Departamento de Ingeniería y Arquitectura, Universidad del Valle de Atemajac Querétaro, México; E-mail: dra.rubivazquez@gmail.com
} 


\section{INTRODUCCIÓN}

Las tendencias mundiales apuntan hacia el estudio de sistemas de ciudades y la expansión urbana de las zonas metropolitanas. A nivel internacional, investigadores, instituciones y gobiernos, le han dado importancia al estudio del fenómeno urbano del proceso de metropolización, caracterizándose por ser dinámico, evolutivo y trascendente para la comprensión de los nuevos asentamientos en todas las ciudades del mundo (UN-HÁBITAT, 2012).

El proceso de metropolización representa el crecimiento de una gran ciudad (principal) que va integrando territorios contiguos, por procesos de expansión o conurbación hasta configurar una zona metropolitana; se caracteriza por una alta concentración-atracción de población y actividades económicas especializadas (Icazuriaga, 1992:24; e Iracheta, 2009:51).

En el caso de México, de acuerdo a las proyecciones del Programa de las Naciones Unidas para los Asentamientos Humanos y Naciones Unidas para el Medio Ambiente; indican que para el 2030 el $83.3 \%$ de la población total se concentrará en áreas urbanas y el principal crecimiento se dará en ciudades intermedias entre 100 mil y 999 mil habitantes, por lo que en México existirán 20 ciudades de más de un millón de habitantes (UN-HÁBITAT, 2011:10).

Es evidente que la transición urbana que experimentan las ciudades mexicanas intermedias, hacia configurarse como Zonas Metropolitanas $(\mathrm{ZM})$, es un fenómeno complejo, gestado en nuestro país desde 1960, cuando se reconocieron las primeras $12 \mathrm{ZM}$ representando el $25.6 \%$ de la población total. La evolución de las zonas metropolitanas se manifiesta en 2010 con $59 \mathrm{ZM}$ concentrando el $55.8 \%$ de la población total (UNHÁBITAT, 2011:75).

Hoy en día, se presenta una clara tendencia hacia el proceso de metropolización en las ciudades mexicanas que integran el sistema urbano nacional. En 2005, se delimitaron $56 \mathrm{ZM}$ y para el 2010 se identificaron 59 (CONAPO, 2004; CONAPO, 2010). Además de incrementarse en pocos años, en la delimitación de cada una de las $\mathrm{ZM}$, se realizaron modificaciones, al incorporarse en 2010 nuevos municipios a las delimitaciones ya publicadas en 2005.

La problemática urbana a la que hoy se enfrenta México se deriva de la situación de la población urbana en el mundo y las tendencias globales del proceso de metropolización.
Existen pocos estudios sobre las nuevas estructuras territoriales relacionadas al proceso de metropolización y su importancia radica en el conocimiento de las necesidades de las ciudades, destinadas a las sociedades y culturas del siglo XXI. En este sentido, se distinguen los siguientes puntos:

Primero, la estructura territorial en proceso de metropolización, continúa creciendo y en un proceso dinámico de adaptación se modifica independientemente a las delimitaciones políticoadministrativas, lo cual detona problemáticas diversas en relación a la dotación de todos los servicios municipales, infraestructura de transporte, calidad de vida y administrativamente repercute en la recaudación y la planificación urbana de los municipios.

Segundo, es conocido el hecho de que el proceso de urbanización acelerado en las ciudades mexicanas, no siempre es equivalente a su crecimiento económico. Se ha observado que el crecimiento urbano excesivo ha provocado altos índices de pobreza urbana, sobrepoblación y proliferación de asentamientos irregulares. Por lo cual, el término proceso de metropolización podría no significar un progreso de las ciudades hacia un crecimiento equilibrado y sustentable.

Tercero, la delimitación Zona Metropolitana (ZM), no en todos los casos corresponde a una situación de articulación urbana o un buen funcionamiento; por lo cual se decidió investigar si las ZM responden simplemente a una nueva división político administrativa, o cuáles son las nuevas características que presentan las ciudades $\mathrm{ZM}$ en su estructura territorial.

Con el objetivo de conocer y explicar el proceso de metropolización en las ciudades de México, se selecciona el caso de la Zona Metropolitana de Querétaro (ZMQ), ya que al año 2013 ha rebasado sus límites político-administrativos, destaca en competitividad urbana en relación al sistema de ciudades y ocupa el lugar número diez (10) dentro del listado de ZM por tamaño poblacional a nivel nacional (CONAPO, 2012; Sobrino, 2010).

Como primer acercamiento a la comprensión de la complejidad de una estructura urbano regional, se analizó la interacción de los cuatro municipios que conforman la ZMQ: Corregidora, El Marqués, Huimilpan y Santiago de Querétaro. Se observa a través de cartografía e imágenes satelitales que la conurbación se ha dado entre los municipios. 
Debido a esta tendencia y a los tres puntos mencionados anteriormente, se considera que actualmente es necesario realizar investigación científica sobre las transformaciones en la estructura territorial de la ZMQ; por lo cual se intenta dar respuesta a la siguiente pregunta: ¿De qué manera la oferta de suelo urbano de bajo precio y la inmigración de población ejercen una influencia significativa sobre el proceso de metropolización y el crecimiento urbano disperso en la estructura territorial de la Zona Metropolitana de Querétaro entre 1990-2010?

La hipótesis plantea que en la Zona Metropolitana de Querétaro el crecimiento urbano disperso se produce en función de la localización espacial de la oferta de suelo urbano y la dinámica de inmigración como consumidor. Existe una correlación entre el suelo urbano de bajo precio y el proceso de metropolización de la estructura territorial en los cuatro municipios de la Zona Metropolitana de Querétaro entre 1990-2010.

El periodo de estudio se considera de 1990 a 2010, con lo que se pretende explorar los orígenes y los cambios que se observan a partir del boom de la industrialización de 1960 y diez años después en 1970 como punto de referencia de la transformación urbana. Asimismo, otros antecedentes que han sido factores relevantes para el proceso de metropolización, como la migración hacia la ZMQ a partir del terremoto en el D.F. en 1985 y recientemente el fenómeno de migración debido a la inseguridad en otros estados.

Actualmente, se desconocen los efectos del proceso de metropolización en su relación con la problemática del crecimiento urbano de tipo disperso; se identifica que la ZMQ no se ha estudiado suficientemente y se requiere de investigación para fundamentar y generar normatividad, nuevas metodologías e instrumentos de Planeación Urbana adecuados para la escala metropolitana de las ciudades mexicanas del futuro.

\section{METODOLOGÍA}

De acuerdo a la delimitación oficial de Zonas Metropolitanas (CONAPO, 2010), para la ZMQ se seleccionaron los municipios de: Corregidora, El Marqués, Huimilpan y Santiago de Querétaro; ya que se requiere analizar los cuatro municipios para obtener la información completa de la ZMQ.
El tamaño de la muestra contempla la observación de 10 asentamientos periféricos por cada municipio, resultando un total de 40 reactivos. Para la muestra seleccionada, se recopilaron los datos socioeconómicos de los censos cada 10 años, 1990, 2000 y 2010; con el objeto de observar el comportamiento de las variables cada 10 años (proceso de metropolización, inmigración interestatal, crecimiento urbano disperso, precio bajo del suelo y población total).

Asimismo, se observaron los datos a partir de 1995 cuando se iniciaron los conteos; lo anterior debido a que se realizan cada 5 años y se han utilizado para poder dar certeza al censo, a partir de estos conteos se han realizado las proyecciones actuales. En la primer variable proceso de metropolización, se observaron fotografías aéreas a través de las cuales se generaron polígonos de los rasgos físicos y la urbanización en los cuatro municipios. Paralelamente se revisó la información de los vuelos fotogramétricos siguientes años: 1993, 2000 y como el más reciente se encuentra el del 2006.

A partir de esto, se estudió la evolución de la urbanización a través del tiempo y sus relaciones con los nuevos asentamientos y el crecimiento metropolitano de la estructura territorial.

A una escala metropolitana, la metodología de análisis cartográfico aplicado comprende una contrastación de la parte gráfica con los datos duros obtenidos mediante un sistema de información geográfica (SIG).

En este proceso, se requirieron los siguientes métodos: Método comparativo cartográfico, Método de la malla y Método de sobre posición de capas, así como una combinación de técnicas para la construcción de planos temáticos en el software ArcGis en conjunto con la elaboración de fichas para el Análisis Urbano.

\section{LOS PROCESOS DE METROPOLIZACIÓN EN MÉXICO}

En México, los orígenes de la investigación científica en el tema del Proceso de Metropolización se remontan al surgimiento de trabajos pioneros como el "Ensayo para la delimitación de la zona metropolitana de la Ciudad de México en 1940, 1950 y 1960", 2 desarrollado por Luis Unikel, uno de los autores más importantes cuyas contribuciones han permanecido a través del tiempo.

2 Unikel, Luis (1960), Ensayo para la delimitación de la Zona Metropolitana de la Ciudad de México en 1940, 1950 y 1960, México, COLMEX. 
En 1976, Crescencio Ruiz Chiapetto, Gustavo Garza y Luis Unikel presentan la primera edición del libro "El Desarrollo urbano de México. Diagnóstico e implicaciones futuras", ${ }^{3}$ el cual marcó el inicio de una nueva era en el campo del urbanismo mexicano, haciendo referencia a los rasgos generales que caracterizan las ZM. A partir de los cuales, se establecieron los criterios analíticos para definir las distintas etapas del Proceso de Metropolización; las aportaciones radican en la innovación en relación a los distintos métodos para la delimitación de ZM, las unidades de análisis y una propuesta de fases de metropolitanismo. A lo largo del documento, los autores advierten desde los años setenta sobre los riesgos y problemas de caer en la urbanización excesiva $y$ sin regulación en las ZM. Posteriormente, en 1981 la autora Margarita Nolasco presenta las políticas para el desarrollo metropolitano y analiza el fenómeno a partir de la Teoría de la Dependencia. ${ }^{4}$ Otras investigaciones destacaron por la aplicación de un análisis comparativo entre las ciudades intermedias, como ejemplo cabe citar el caso de León, San Luis Potosí y Torreón que presenta Héctor Salazar en 1984. ${ }^{5}$ Por su parte, en 1986 la autora Eugenia Negrete y Héctor Salazar proponen las primeras Zonas metropolitanas de México en $1980 .^{6}$ En seguimiento, surgieron otros trabajos que analizaron la Metropolización y la política urbana en la Ciudad de México hacia 1988, los cuales fueron realizados por Alfonso Iracheta y Emilio Duhau. ${ }^{7}$ En esta misma dirección, durante la siguiente década la autora Carmen Icazuriaga desarrolla en 1992 una hipótesis sobre el proceso de metropolización y construye uno de los referentes teóricos más sobresalientes de los años noventa. ${ }^{8}$ Por otra parte, en los estados se distinguen los estudios de caso que abordan los procesos de metropolización existentes en las ZM de Monterrey (Garza et al., 1999; Bassols, 2006), ${ }^{9}$ el Valle de México, Guadalajara y Toluca (Icazuriaga, 1992; Iracheta, 2009). ${ }^{10} \mathrm{Y}$ en la ciudad de Puebla (Flores, 1993; Iracheta, 2012). ${ }^{11}$

Del análisis documental sobre el estado del arte, puede apreciarse que las contribuciones de los autores mencionados anteriormente, en conjunto con Carlos Garrocho, ${ }^{12}$ Jaime Sobrino, Javier Delgado, $^{13}$ y Roberto Eibenschutz, ${ }^{14}$ han conformado un cuerpo de conocimientos sólido y valioso que es importante retomar para fundamentar las investigaciones de las próximas generaciones. A continuación, con el propósito de acercar al lector hacia las diferentes perspectivas que han sido utilizadas en los estudios sobre el fenómeno urbano del proceso de metropolización; se presenta una selección de trabajos de relevancia, que han sido reconocidos por sus contribuciones, contenido teórico y metodológico.

Desde la perspectiva físico-espacial, Delgado (1993) desarrolla el concepto de la ciudad-región aplicado en la ciudad de Querétaro; mediante el cual analiza el proceso de metropolización en su relación con tres esquemas físico-espaciales: centro-periferia, ciudades en expansión y fragmentación-rearticulación metropolitana (Delgado, 1993: 656). Explora los cambios en la estructura territorial de las ciudades en expansión hacia convertirse en metrópolis, a partir de nueve aspectos identificables:

3 Unikel, Luis et al. (1976), El desarrollo urbano de México. Diagnóstico e implicaciones futuras, México, COLMEX.

4 Nolasco, Margarita (1981a), Cuatro ciudades. El proceso de urbanización dependiente, México, INAH.

Nolasco, Margarita (1981b), Políticas de desarrollo metropolitano en la Ciudad de México, México, CEPAL.

5 Salazar, Héctor (1984), Dinámica del crecimiento de las ciudades intermedias en México: Los casos de León, San Luis Potosí y Torreón (1970-1980), México, COLMEX.

6 Negrete, Eugenia y Salazar, Héctor (1986), Zonas metropolitanas en México 1980, México, COLMEX.

7 Iracheta, Alfonso (1988), Metropolización y política urbana en la Ciudad de México, México, COLMEX.

Duhau, Emilio (1988), Planeación metropolitana y política urbana municipal en la Ciudad de México, México, UAM

8 Icazuriaga, Carmen (1992), La Metropolización de la Ciudad de México a través de la instalación industrial, México, CIESAS.

9 Bassols, Mario (2006), Explorando el régimen urbano en México: Un análisis metropolitano, México, UAM.

Garza, Gustavo et al. (1999), Políticas urbanas en grandes metrópolis: Detroit, Monterrey y Toronto, México, COLMEX.

10 Iracheta, Alfonso (2009), Políticas públicas para gobernar las metrópolis mexicanas, México, El Colegio Mexiquense.

11 Flores, Sergio (1993), Desarrollo Metropolitano. Análisis y Perspectivas, México, BUAP.

Iracheta, Alfonso (2012), Metrópolis en crisis: una propuesta para la zona metropolitana Puebla-Tlaxcala, México, BUAP.

12 Garrocho, Carlos y Sobrino, Jaime (1995), Sistemas Metropolitanos: Nuevos enfoques y prospectiva, México, COLMEX.

13 Delgado, Javier (1993), “Querétaro: hacia una ciudad región”, en Revista Estudios Demográficos y Urbanos, El Colegio de México,

Vol. 8, núm. 3, septiembre-diciembre, pp. 655-699.

14 Eibenschutz, Roberto y Goya Comps. (2009a), Estudio de la integración urbana y social en la expansión reciente de las ciudades en

México, 1996-2006: dimensión, características y soluciones, México, UAM.

Eibenschutz, Roberto y Benlliure (2009b), Mercado formal e informal del suelo. Análisis de ocho ciudades, México, Porrúa. 
1. Conurbación de poblados preexistentes en su periferia inmediata; 2 . El desdoblamiento hacia las áreas intermedias de nuevos núcleos comerciales; 3. Grandes equipamientos; 4. Servicios públicos; 5. Conjuntos habitacionales; 6 . Papel expansivo de los libramientos; 7. Pautas de localización de la industria; 8. Creación de red suburbana de transporte; 9. Indicios de una corona metropolitana no conurbada pero fuertemente enlazada al centro. Complementariamente, el autor utiliza el modelo de las fases de crecimiento para explicar la transformación en el crecimiento urbano de Querétaro. Relata que este modelo no puede explicar comparativamente dos ciudades, es decir resolver porqué una ciudad en expansión crece más que otra; el modelo tampoco podría determinar si un proceso de transformación hacia metrópolis es mejor en una ciudad o en otra. Dicho modelo únicamente es útil para analizar la evolución de los cambios que se presentan en una ciudad y ponderar la dimensión socio-política sobre el territorio.

Delgado (1993) expresa lo siguiente: "es necesario continuar con las investigaciones a nivel transregional, por un lado, hacia el complejo de ciudades del Bajío y por otro, del papel que San Juan del Río puede jugar como punto intermedio en el enlace con la ciudad de México. Tal vez estamos presenciando el fin de la ciudad-ciudad y el inicio de la ciudad-región. Tal vez sea un eslabón que facilite la construcción de megalópolis" (Delgado, 1993: 693).

Desde la perspectiva multidisciplinaria, uno de los trabajos más avanzados y completos a nivel nacional en relación al cuerpo de conocimientos existente es la tesis de Sousa (2006), ${ }^{15}$ presenta la cualidad de permitir la descripción y el análisis de un fenómeno tan complejo como el proceso de Metropolización en Monterrey desde una perspectiva integral. Las metodologías que se utilizaron son el Modelo para el Análisis de las tendencias de ocupación del suelo metropolitano, así como simulaciones de la expansión urbana.

El rasgo más importante, es que experimenta con un sistema para el análisis de la dispersión y aplica métodos tradicionales estadísticos y gráficos para el conocimiento de la dinámica poblacional, representados en el área metropolitana de Monterrey.

Desde la perspectiva sociológica, en el estudio de Tapia (2009), ${ }^{16}$ se selecciona la Teoría del Cambio Social para interpretar el proceso de urbanización, como agente directo y causal de las transformaciones que se manifiestan en las comunidades y localidades rurales. A partir de las condiciones de subordinación en la localidad San Pedro Totoltepec, aborda el cambio urbano y social en Toluca durante el periodo 1990-2000. Respecto al proceso de metropolización, realiza algunas precisiones muy interesantes sobre los movimientos campo-ciudad, para explicar que actualmente el movimiento ocurre también a la inversa, de la ciudad hacia el campo. Lo anterior, porque en el fenómeno se presenta la instalación y apertura de nuevas zonas residenciales, industriales y comerciales como resultado de la desconcentración de las actividades urbanas. Se observa, por lo tanto, que pueden identificarse procesos de urbanización distintos a los que se conocieron entre los años 1940 y 1980. En la metodología aplicada, se utiliza como unidad de análisis el área geo estadística básica (AGEB), para obtener los datos socioeconómicos y se estudia la tipología de los usos de suelo en relación a dos cortes censales 1990 y 2000.

Desde la perspectiva de una Génesis del Proceso de Metropolización, se reconoce el estudio sobre el caso de Guadalajara desarrollado por Tovar (2010). ${ }^{17}$ En el que presenta una crítica muy interesante sobre el fenómeno, que se podría clasificar como una postura en oposición a las interpretaciones ya conocidas sobre los procesos de metropolización en México; puesto que hace referencia al caos metropolitano. En primer término, el autor inicia por describir claramente las diferencias entre: la metropolización, el proceso de metropolización, conurbación, aglomeración urbana y la conversión de ciudad a metrópoli. En un segundo momento, respecto a la génesis del fenómeno se hace referencia al México rural del siglo XX y su transición hacia convertirse en un país mayormente urbano, el cual presenta varias tendencias hacia iniciarse como un país metropolitano desde los inicios del siglo XXI.

\footnotetext{
15 Sousa, Eduardo (2006), El Área Metropolitana de Monterrey: análisis y propuesta de lineamientos metodológicos para la planeación en zonas periféricas, Tesis Doctoral en Filosofía con Orientación en Arquitectura y Asuntos Urbanos, México, UANL.

16 Tapia, Jorge (2009), Cambio socioterritorial en el contexto de las metrópolis, en Dinámicas Ambientales y Territoriales en México. Una disciplina multidisciplinaria, México, UAEM.

17 Tovar, Edgar (2010), “Génesis del proceso de Metropolización en Guadalajara”, en Revista Territorios Metropolitanos Artículos y ensayos de investigación, Vol. 03, núm. 03-04, junio-diciembre, pp. 5-18.
} 
Como dato adicional Tovar (2010) indica lo siguiente: "El proceso de Metropolización es dinámico, gradual y en México alcanzó dimensiones que preocupan a diversos especialistas porque, hasta el momento, la velocidad del proceso ha superado los intentos por controlarlo y dirigirlo. El caos de las ciudades metropolitanas mexicanas es un hecho palpable" (Tovar, 2010: 6). Destacan dos hallazgos en sus contribuciones, en un primer hallazgo identifica las siguientes tres problemáticas que por su relevancia para el análisis, se citan textualmente con el objetivo de advertir los posibles escenarios a los que podría enfrentarse la investigación del fenómeno.

1. Problemática sobre los límites políticoadministrativos: "los límites administrativos no coinciden con los límites reales del proceso de desarrollo de los núcleos urbanos, lo que produce descontrol y confusión entre las autoridades para dirigir y administrar el proceso de urbanización y las consecuencias de allí derivadas. Esta necesidad de coordinación para la gestión del proceso de urbanización de la ciudad central y de sus núcleos secundarios da vida práctica al proceso de metropolización" (Tovar, 2010: 9).

2. Problemática sobre la delimitación y conteo de Zonas metropolitanas, en la que se cuestiona la metodología de SEDESOL, CONAPO e INEGI: "Porque para señalar que existe un proceso de metropolización en una ciudad que no sobrepasa sus límites municipales, se debe demostrar que su proceso de urbanización, crecimiento y desarrollo influye sustancialmente en el proceso de urbanización, crecimiento y desarrollo de los núcleos urbanos (municipios) vecinos [...] Tarea difícil de medir con los datos disponibles" (Tovar, 2010: 9).

3. Problemática sobre las limitaciones en la medición del fenómeno: "Es un hecho consensuado la imposibilidad práctica de medir plenamente la magnitud de las relaciones que ejerce una ciudad central (o metrópoli) sobre los centros urbanos secundarios, es decir, el grado en que una región sufre un proceso de metropolización. Por lo anterior, también existe una imposibilidad práctica para definir el área de influencia de la metrópoli, es decir, la delimitación de la región, zona o área metropolitana. Además, el fenómeno es dinámico, por lo que los núcleos urbanos que conforman la zona metropolitana son susceptibles de variar con el tiempo" (Tovar, 2010: $10)$.

En un segundo hallazgo, Tovar (2010) propone un método para deducir el momento de inicio en un proceso de Metropolización; y explica que dicho proceso se da entre urbes, no entre localidades. Desde esta perspectiva, entonces es posible determinar un referente del inicio del fenómeno a partir del momento en que las localidades rurales se convierten en localidades urbanas, con base en la situación de sobrepasar los 2,500 habitantes.

En este escenario, respecto a la teoría que se puede tomar como referencia para acercarse hacia la comprensión de los Procesos de Metropolización, se propone la Teoría del Continuum Urbano Rural. La cual analiza las localidades netamente rurales y las localidades completamente urbanas, en su relación con un continuo proceso de cambio en el que no existe un límite que marque el paso de un estado a otro. En este sentido, aclara que es factible encontrar la génesis del fenómeno a partir del análisis e identificación de la ZM, en función de la ciudad central y la influencia que ejerce hacia los núcleos secundarios. Finalmente, señala que no es una condicionante la cuestión de que los núcleos urbanos secundarios tengan una continuidad física respecto al núcleo urbano central (Tovar, 2010: $10)$.

Desde la perspectiva económica, en el contexto de las metrópolis mexicanas la autora Negrete (2010), ${ }^{18}$ presenta los criterios para determinar la jerarquía de una metrópoli; entendida como la ciudad principal de la región al compararse en extensión con otros territorios colindantes, sobre la cual establece lo siguiente: "Remite a relaciones asimétricas de poder y subordinación y, por ende, a vínculos funcionales de dependencia" (Negrete, 2010: 175).

$\mathrm{Al}$ respecto, cabe destacar los aspectos económicos que la autora recomienda observar, cuando se examinan los rasgos que definen y caracterizan a la metrópoli: la dimensión demográfica, la competitividad urbana, la función políticoadministrativa y la influencia regional.

Negrete (2010), aclara que no puede jerarquizar a las metrópolis en base al tamaño poblacional, pero si en base a su atractividad poblacional; y su competitividad entendida como el "grado en el cual una ciudad, en comparación con otras

18 Negrete Salas, Eugenia (2010), Las metrópolis mexicanas: Conceptualización, gestión y agenda de políticas, en Los Grandes Problemas de México Vol. II, Desarrollo Urbano y Regional, México, COLMEX. 
ciudades en competencia, es capaz de atraer inversiones productivas que se traducen en generación de empleos e incremento en los ingresos" (Negrete, 2010:187).

Desde la perspectiva política, el trabajo de Vargas (2011), ${ }^{19}$ analiza los problemas derivados del proceso de metropolización en la ciudad de Pachuca, desde el punto de vista de la gestión metropolitana. Aborda los problemas en la coordinación de los servicios públicos indispensables para los habitantes de la ciudad. Recomienda que para resolver estos problemas, puede ser de utilidad considerar en el análisis a los cuatro municipios que conforman la conurbación (Vargas, 2011: 145). A partir de los datos analizados sobre las políticas urbanas y el poder local, el estudio se enfoca en la urbanización y la conurbación, como procesos generadores de problemáticas y conflictos de carácter social y urbano.

Desde la perspectiva ecléctica, entre las múltiples aportaciones de Sousa (2012), ${ }^{20}$ destaca el concepto metrópolis prematura y el análisis de la Transformación espacial y sus procesos intervinientes, los cuales se desarrollan para explicar la configuración espacial de Monterrey entre 1940-2010 a partir de los tres procesos por los que atraviesa la metrópolis. (Sousa, 2012: 62). Los hallazgos del autor se distinguen por la creación de modelos explicativos y los esquemas correspondientes para los siguientes procesos: 1) Proceso iterativo de Metropolización, basado en la velocidad del ciclo reproductor de la vida de los pobladores; 2. Proceso iterativo de Metropolización, basado en una situación antinómica de planeación; y 3) Proceso iterativo de Metropolización, basado en la actividad productiva de los pobladores, el ciclo reproductivo y la antinomía de planeación.

En este sentido, lo que resulta más significativo entre las valiosas contribuciones del autor, es el análisis de las combinaciones posibles entre los tres modelos enumerados; para explicar la transformación de una ciudad hacia convertirse en un centro metropolitano. Concluye que no es suficiente abordar el proceso de Metropolización desde una perspectiva única y como solución propone una perspectiva ecléctica.
Finalmente en este apartado, mediante la recopilación de los aspectos clave, se intenta mostrar al lector las consideraciones y dificultades que intervienen al abordar una investigación de esta índole. Otro punto que cabe destacar, es que la perspectiva a utilizar para el análisis determina la utilidad de los resultados de investigación; por lo cual, se selecciona el enfoque de Análisis Territorial, como el más adecuado para estudiar la dinámica territorial en la escala metropolitana correspondiente al proceso de metropolización que experimentan Querétaro y su ZM.

\section{EL PROCESO DE METROPOLIZACIÓN EN QUERÉTARO DESDE LA PERSPECTIVA DE ANÁLISIS TERRITORIAL}

Teóricamente el enfoque de Análisis Territorial, plantea que cada uno de los elementos del territorio puede referenciarse a los subsistemas que integran el sistema urbano-regional. El territorio para su estudio se estructura en seis (6) Categorías de Análisis Territorial: 1) económica, 2) urbana, 3) social, 4) ambiental, 5) política, 6) cultural. Además de un subnivel con siete (7) Subcategorías de análisis territorial: 7) subsistema económico, 8) demográfico, 9) transporte, 10) uso de suelo, 11) localización de los servicios, 12) localización de la vivienda y 13) localización del empleo (véase en Figura No. 1) correspondiente al esquema (Vázquez, 2011). Interpretando lo anterior en una matriz, colocando verticalmente los elementos del territorio y horizontalmente los subsistemas del sistema urbano-regional; se puede establecer que existen organizaciones, correlaciones y patrones que son observables y comprobables dentro del territorio. Espacialmente, se identifica que las interacciones entre los elementos del territorio y los subsistemas del sistema urbano regional, son cuantificables en tiempo, distancia y frecuencia; con esto se distingue, que las unidades cuantificables son aplicables y comunes, para un análisis desde la perspectiva económica, geográfica o urbana. Mediante distintas escalas de observación, el enfoque del análisis territorial nos lleva hacia un conocimiento más amplio y estructurado de todos los aspectos que habrá que considerar como antecedente para fundamentar el estudio del proceso de metropolización.

\footnotetext{
19 Vargas, Pablo (2011), “La conflictividad en el Proceso de Metropolización de Pachuca”, en Revista Papeles de Población, Vol.17, núm.68, abril-junio, pp. 127-146.

20 Sousa, Eduardo (2012), “De la ciudad a la metrópolis prematura: Los tres procesos”, en Revista Urbano, Vol. 15, núm. 26, noviembre, pp. 54-64.
} 
En lo referente a la aplicación del enfoque en otras investigaciones, se identifica que se ha utilizado por (Sousa, 2006; Indovina, 2007; Vázquez, 2011; y Vázquez, 2018). Lo que resulta más significativo, es que dicho enfoque corresponde en algunas de sus categorías, con los ejes planteados por Naciones Unidas en su documento origen de la Declaración de Vancouver sobre los Asentamientos Humanos (UN-HÁBITAT, 1976). El enfoque de Análisis Territorial, ${ }^{21}$ se sustenta en teorías generales, teorías sustantivas y conceptos, que desde la perspectiva económica, geográfica y urbana se fusionan y complementan, conformando conceptos más amplios o generales (Isard, 1960; Secchi, 1968; Chorley y Hagget, 1971; Hall et al., 1975; Harris et al., 1975; Stuart, 1977; Hagget, 1979; Wilson, 1980 y Johnson, 1987).
De acuerdo a Pujadas (1998) "El análisis territorial se ha de apoyar tanto en el conocimiento teórico interdisciplinar, como en un conjunto amplio de instrumentos de análisis de carácter más metodológico, que han de permitir explicar conjuntamente los procesos territoriales. Se nutre de un amplio bagaje de conocimientos teóricos y metodológicos" (Pujadas, 1998: 36).

Al respecto, se presenta el enfoque de análisis territorial como la primer estructura de análisis para mejorar la comprensión sobre el proceso de metropolización, cabe destacar la importancia de su cualidad multidisciplinar tal como puede observarse a continuación (véase en la Figura No.1) esquema a partir del cual, se describen las categorías de análisis territorial. ${ }^{22}$

Figura 1. Esquema- El enfoque de análisis territorial aplicado al proceso de metropolización

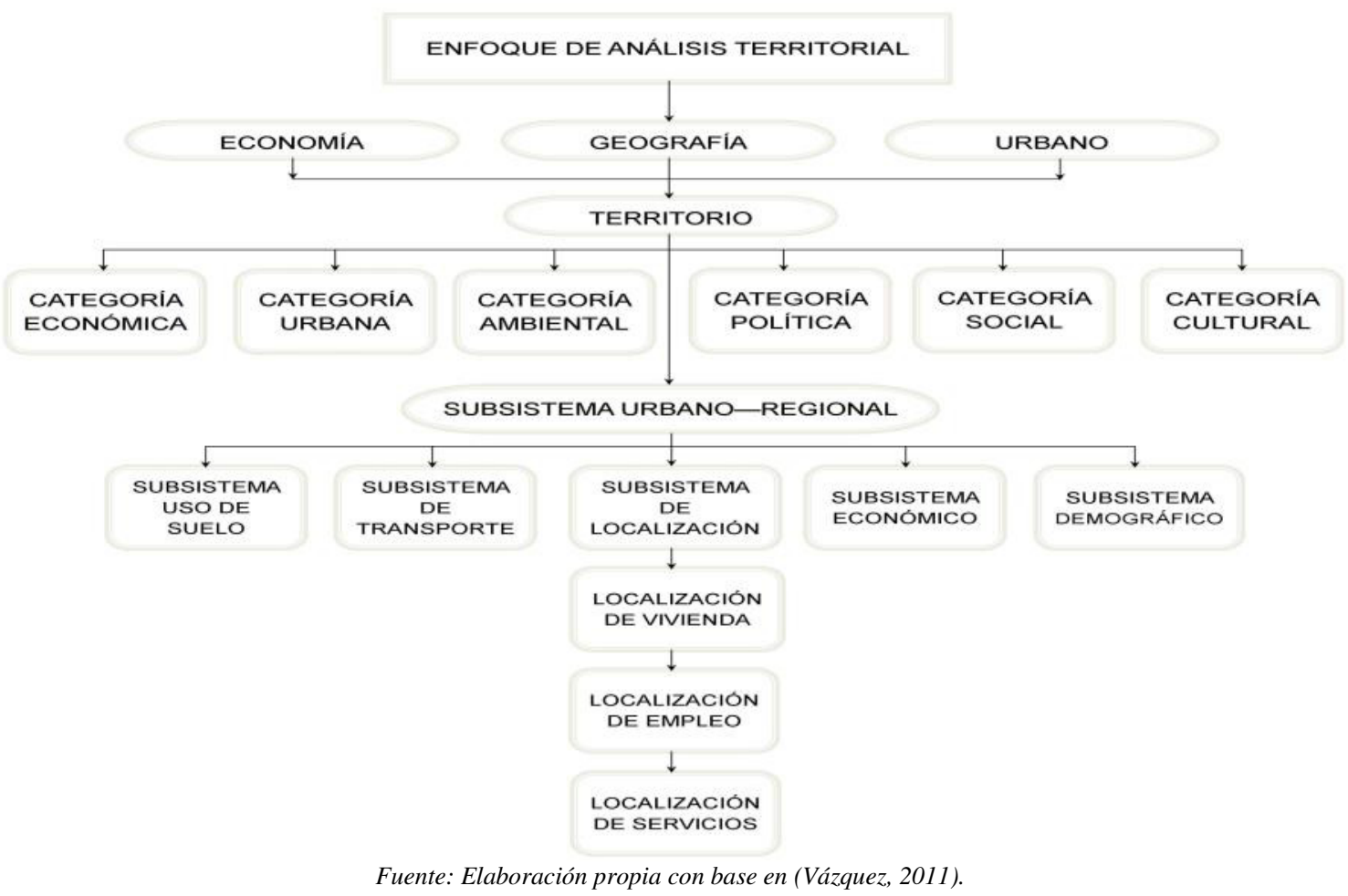

21 Isard, Walter (1960), Métodos de Análisis Regional, Barcelona, Ariel.

Secchi, Bernardo (1968), Análisis de las Estructuras Territoriales, Barcelona, Gustavo Gili.

Chorley, Richard y Peter Haggett (1971), La Geografía y los Modelos Socioeconómicos, Madrid, Methuen.

Hall, Peter et al. (1975), Modelos de Análisis Territorial, Barcelona, Oikos-tau.

Harris, Britton et al. (1975), Modelos de Desarrollo Urbano, Barcelona, Oikos-tau.

Stuart, Chapin (1977), Planificación del Uso de Suelo Urbano, Barcelona, Oikos-tau.

Hagget, Peter (1979), Geography a Modern Synthesis, New York, Harper International.

Wilson, A.G. (1980), Geografía y Planeamiento Urbano y Regional, Madrid, Oikos-tau

Johnson, James (1987), Geografía urbana, España, Oikos-tau.

22 Vázquez Cruz, Rubí del Rocío (2011), Propuesta Metodológica para la formulación de un Modelo de Ordenamiento Territorial,

Tesis de Maestría en Planeamiento Urbano y Regional, México, UGTO. 
1. En la categoría urbana, desde la perspectiva de análisis territorial la autora Vázquez (2018), desarrolla la siguiente definición: "El proceso de metropolización es un proceso socioeconómico y demográfico que se manifiesta en el territorio física y espacialmente mediante un tipo de crecimiento urbano en el cual la localización de los asentamientos de una ZM se presenta de manera dispersa en zonas periféricas de sus distintos municipios y zonas alejadas de la ciudad principal. En este ciclo, vincula a las ciudades en la organización de una estructura territorial de escala metropolitana" (Vázquez, 2018:323).

Actualmente, se conoce que el proceso de metropolización dentro de la línea de evolución conceptual de la ciudad se ubica en una etapa de crecimiento previa a la metropolización y a la metrópolis. Puede definirse como una fase de expansión secuencial de la ciudad en la que independientemente de los límites políticoadministrativos de cada uno de los municipios que integran la ZM, se presenta el crecimiento de la estructura territorial a través de toda la extensión el territorio metropolitano como unidad.

Vázquez (2018), articula la línea de evolución conceptual de la ciudad mediante siete (7) fases en el siguiente orden de acuerdo al grado de avance en su desarrollo: "1) la ciudad intermedia; 2) la ciudad región; 3) el proceso de metropolización; 4) la metrópolis; 5) la metropolización; 6) la megalópolis y 7) la metápolis" (Vázquez, 2018: 69).

En trabajos anteriores se ha mencionado que en la transformación de una ciudad-región hacia convertirse en metrópolis la ciudad experimenta un proceso de metropolización. Una manera de explicar el fenómeno es a partir de sus efectos más evidentes en el territorio entre los cuales se identifica el crecimiento urbano de tipo disperso.

De acuerdo a Vázquez (2018), este fenómeno se caracteriza por la aparición de los siguientes rasgos específicos en la estructura territorial metropolitana, a partir de los cuales es posible definir si realmente existe un proceso de metropolización:

"organización del territorio; cambio en las jerarquías territoriales; nuevas centralidades; cambio de un modelo monocéntrico a otro policéntrico; policentrismo; polinuclearización; conurbación; integración; infraestructuración; difusión o dispersión; diversificación de los servicios; mercantilización; especulación del suelo; especialización de los servicios y de las actividades económicas" (Vázquez, 2018:319).

En seguimiento a la categoría urbana, Vázquez (2018) desarrolla una explicación general y menciona que el proceso de metropolización inicia con un ciclo económico-administrativo de especulación del suelo en el que interviene la asignación de un precio bajo al suelo en predios rústicos y urbanos, los cuales se compran en extensiones significativas de metros cuadrados (m2) y hectáreas (Ha), precisamente por su bajo costo en macro lotes o grupos de predios que se reflejan en la expansión de la superficie de urbanización de una ZM a través del tiempo.

A partir de la Teoría de la Subasta del Suelo Urbano, se identifica que la localización espacial del suelo urbano de bajo precio en una ZM, genera la instalación de fraccionamientos en distintos puntos de ubicación de una manera desordenada y dispersa en periferias, zonas alejadas de la ciudad principal e indistintamente de las características del medio físico natural; todo el suelo es urbanizable como resultado de la especulación urbana.

Esta condición de crecimiento urbano tipo disperso, paralelamente a una alta concentración de población e inmigración de habitantes, tiene afectaciones directas en la organización de la estructura territorial metropolitana porque al instalarse un fraccionamiento en una zona aislada, se requiere la infraestructuración mediante nuevas vías terrestres y la dotación de todos los servicios públicos para su funcionamiento, una mayor cobertura de los centros de educación, gobierno y esparcimiento. Lo que promueve la mercantilización de la ciudad como parte del proceso de metropolización, mediante la diversificación de actividades económicas y la especialización de los servicios metropolitanos (Vázquez, 2018:319).

2. En la categoría ambiental, el proceso de metropolización en Querétaro se asocia con el modelo insustentable de crecimiento urbano disperso en el cual se presenta la localización de centros de trabajo, servicios y vivienda, ubicados en zonas muy alejadas que promueven un aumento en el uso del automóvil. Entonces, en una ZM al recorrer trayectos de mayor distancia en automóvil se genera: 1) una mayor emisión de contaminantes y 2) un incremento del gasto en gasolina por habitante, lo que tiene repercusiones económicas para las familias y para el medio ambiente. 
Por lo tanto, el modelo de crecimiento urbano se encuentra correlacionado con la contaminación del aire, la calidad de vida y la economía de los habitantes.

En este sentido, como resultado de la sobrepoblación que se presenta en algunas zonas metropolitanas derivada de los procesos de inmigración poblacional, se presenta la saturación de los rellenos sanitarios municipales y se genera la contaminación en ríos, lagos y pozos de agua. Esta problemática produce afectaciones al ambiente natural que conforma un territorio, en los suelos, la vegetación, el cambio climático, la cantidad de polen en el aire (Hernández y Ojeda, 2019); y sobre las especies que habitan en los ecosistemas terrestres y acuáticos de una región.

Entre los efectos de la urbanización expansiva y dispersa, destacan los cambios de uso del suelo que pueden observarse al contrastar las imágenes aéreas de GoogleEarth con los Planes de Desarrollo Urbano, ya que en ocasiones se consumen las reservas territoriales de suelo a través del tiempo sin considerar el valor ecológico del medio físico natural y el desarrollo sostenible.

3. En la categoría económica, el proceso de metropolización se asocia a la especulación del suelo como generador del crecimiento urbano de tipo disperso, de acuerdo a la Teoría de la Ocupación del Suelo.

Por otra parte, la estructura territorial del modelo monocéntrico clásico se modifica para crear una nueva distribución de las actividades, que asegure el mayor beneficio económico mediante una polinuclearización acompañada de servicios, comercios, industria y zonas habitacionales que se expanden a través de todo el territorio conformando un nuevo modelo de ciudad.

En este proceso socioeconómico, se promueve la diversificación, mercantilización, especialización y terciarización de los servicios en la escala territorial metropolitana, lo cual se relaciona precisamente con esta nueva organización de extender a través de toda la ZM una estructura territorial que asegure la acumulación de capital en todos los puntos del territorio.

A partir de estas condiciones puede distinguirse en la estructura territorial metropolitana: 1) el policentrismo por referirse a varias centralidades y 2) la polinuclearización por hacer referencia a varios núcleos urbanos (Vázquez, 2018: 324).

4. En la categoría política, el proceso de metropolización se relaciona con las gestiones del recurso federal de los fondos metropolitanos, cuyo objetivo es beneficiar social y económicamente a las $\mathrm{ZM}$. Al respecto, la inversión del recurso de los fondos aplicado en obra pública de infraestructura vial, no en todos los casos resuelve la problemática del crecimiento urbano disperso que se presenta en el contexto del proceso de metropolización.

Lo anterior, porque para conectar a los nuevos fraccionamientos aislados, desintegrados y periféricos con la estructura territorial ya existente, se requieren miles de kilómetros y millones de pesos de recursos públicos que deben asignarse para solucionar este problema de falta de infraestructura; cuando el problema ha sido causado por la especulación urbana que genera el crecimiento urbano disperso en Querétaro y su $\mathrm{ZM}$.

En contraste, haciendo una comparativa con la ciudad de Aguascalientes, que destaca a nivel nacional por su estructura ordenada en la que se distinguen varios anillos viales concéntricos y distribuidores axiales, puede observarse una clara intervención de la planificación urbana y verificarse mediante herramientas digitales como GoogleTimelapse. En este sentido, puede señalarse que sí existen ciudades mexicanas que tuvieron la visión política de preparar la estructura territorial de la ciudad para las próximas generaciones y Aguascalientes puede tomarse como ejemplo a seguir en otras ZM de México.

Entonces, como se ha mencionado, el modelo de ciudad tiene implicaciones directas sobre la calidad de vida de los habitantes y la dotación de los servicios públicos municipales debido a que se requiere una inversión económica muy importante para abastecer a los nuevos fraccionamientos tan alejados, siendo necesaria la instalación de electrificación, redes de agua potable, drenaje sanitario y pluvial, telecomunicaciones $\mathrm{y}$ adicionalmente proporcionarles mantenimientos de vialidades, áreas verdes y la recolección de basura.

5. En la categoría social, en el contexto del proceso de metropolización Indovina (2007), explica la diferencia entre la sociedad que habita en vida comunitaria y la que vive en una metrópolis. Al respecto, compara a la vida en comunidad que puede constituirse por pequeñas ciudades y núcleos de población dispersos los cuales cuentan con una estructura de habitantes que se caracterizan por la cohesión, participación e implicación social al estar involucrados todos sus miembros mediante una misma realidad social, relaciones afectivas y personales, solidaridad, sentido de pertenencia e identidad. 
El autor menciona que en este tipo de organización comunitaria hay un fuerte control social, limitados estímulos culturales, sociales y se da una repetitividad de las experiencias cotidianas (Indovina, 2007: 538).

En contraste, Indovina (2007) manifiesta lo siguiente: "La experiencia de la metrópoli (sociedad), al contrario, fomenta la libertad individual, la multiplicidad de oportunidades, el lado imprevisible de la experiencia cotidiana, pero también propicia la soledad, el anonimato, la segmentación social, la falta de sentido de pertenencia. A su vez, las relaciones y las decisiones no son afectivas, sino de tipo racional" (Indovina, 2007:538).

Derivado de esta cuestión sociológica, Indovina (2007) concluye que en la escala territorial metropolitana se presenta lo siguiente: "el debilitamiento de la identidad ligada al lugar [...] por la simultánea experiencia metropolitana y, por el hecho de que la comunidad local no es, en la mayoría de los casos, enteramente autóctona, sino que está formada por personas de distinta procedencia (incluidos porcentajes más o menos altos de inmigrantes extranjeros). En definitiva, estamos ante una nueva tipología de experiencias" (Indovina, 2007: 539).

6. En la categoría cultural, se ha reconocido la problemática de la ruptura de los valores culturales tradicionales en el contexto del proceso de metropolización, como resultado del deterioro en las condiciones de vida de individuos, familias y sociedades que habitan los asentamientos humanos. De acuerdo a Un-Hábitat (1976), esta situación se relaciona con el agudo desempleo, la pobreza, la enfermedad, el analfabetismo, la discriminación racial y las desigualdades sociales que se presentan principalmente en los países en desarrollo (UN-HÁBITAT, 1976:1141).

Ampliando la mirada, se identifica que las características y los patrones socioculturales de la población que habita en las ciudades y metrópolis, se reflejan en una sociedad y por lo tanto en su cultura como un conjunto. De este vínculo, se deriva la importancia de la preservación de las costumbres, tradiciones y valores culturales que se han conformado a lo largo de la historia de las ZM mexicanas como parte de la identidad regional, de la diversidad nacional y del patrimonio cultural intangible.

En este sentido, respecto al crecimiento urbano de tipo disperso que se ha comentado anteriormente en el contexto del proceso de metropolización de
Querétaro, Un-Hábitat (1976) recomienda lo siguiente: "En la planificación de nuevos asentamientos humanos o en la reestructuración de los existentes debe darse alta prioridad a la promoción de condiciones óptimas y creativas para la coexistencia humana. Esto entraña la creación de un espacio urbano bien estructurado y a escala humana, la estrecha vinculación de las diferentes funciones urbanas, el alivio de las intolerables tensiones psicológicas a que se ve sometido el hombre en las zonas urbanas debido al hacinamiento y al caos, la creación de oportunidades de relaciones humanas y la eliminación de los conceptos urbanos que conducen al aislamiento humano" (UNHÁBITAT, 1976:1150).

Paralelamente, en la escala metropolitana es fundamental la conservación de los monumentos históricos, religiosos o arqueológicos, ya que en ocasiones no son respetados por las nuevas construcciones y deberían ser protegidos de una manera más rigurosa por la normativa urbana, ya que son parte del patrimonio mundial de la humanidad.

Una vez presentado el marco de interpretación general sobre el proceso de metropolización, a través de las categorías del enfoque de Análisis Territorial. A continuación se presenta la segunda estructura de análisis, mediante la cual se intenta describir la ZMQ a partir de cuatro (4) fases del proceso de metropolización en las que coinciden los autores.

De manera sintética se definen como: 1) Urbanización, cuando la ciudad central supera a la periferia en crecimiento anual de población; 2) Suburbanización, cuando la periferia alcanza una mayor tasa de crecimiento porcentual anual; 3) Desurbanización, cuando la ciudad central observa un despoblamiento relativo o absoluto; y 4) Reurbanización, cuando en la ciudad central ocurre un repoblamiento relativo o absoluto (Unikel et al., 1976; Delgado, 1993; Sobrino, 1995 y Sousa, 2010).

En trabajos anteriores Vázquez (2018), explora las siguientes cuatro fases:

1. 1970-1980 Fase de urbanización: en esta fase del proceso de metropolización de Querétaro, (véase en color rojo y azul Figura No.6), en la cual el centro metropolitano presenta desplazamientos menores en el sentido centro periferia, se puede observar que el primer contorno de la ciudad es la delimitación del anillo vial que se encuentra conformado por las siguientes vialidades 
principales: al norte y al este el Boulevard Bernardo Quintana, al sur la Carretera Federal No. 57 y al oeste la Avenida 5 de Febrero.

En la fase de urbanización la ZMQ entre 1970 y 1980 presenta un crecimiento compacto y concentrado, al interior del polígono delimitado por las vialidades ya mencionadas; en el cual no aparece todavía una expansión por fuera de los límites político-administrativos del municipio de Querétaro. Sin embargo, en esta fase inicial puede distinguirse la localización espacial de las localidades que posteriormente dieron origen a los núcleos urbanos que conformaron la estructura territorial polinuclear de escala metropolitana en el 2010.

2. 1990 Fase de suburbanización: el proceso de metropolización en la ZMQ asociado a la década de 1990 (véase en color rosa Figura No.6), en la cual se da inicio al periodo de estudio, se caracteriza por los rasgos de movimientos de descentralización en donde el centro metropolitano, en el cual se dio la concentración, comienza a expandirse y a instalar nuevos asentamientos dispersos en la estructura territorial en correspondencia con el Modelo explicativo de generación de contornos metropolitanos de (Sousa, 2010).

En esta fase de suburbanización, en la organización del territorio se distingue una localización industrial triangular, primero al norte en Querétaro la zona industrial entre Santa Rosa Jáuregui y el límite con Guanajuato hacia San Miguel de Allende y San José Iturbide; segundo al oriente en El Marqués con la zona industrial cercana al aeropuerto internacional y a los límites con los municipios de Pedro Escobedo y Colón; tercero, al poniente en Corregidora con la zona industrial cercana al Pueblito, La Negreta y en el límite con Guanajuato hacia Apaseo el Alto y Apaseo el Grande.

Por otra parte, en la etapa de suburbanización entre 1990 y 2000, el proceso de metropolización se caracteriza por presentar tres tendencias hacia la conurbación: primero, entre Corregidora y Querétaro; segunda, entre Jurica y Santa Rosa Jáuregui; tercera, entre el Marqués y Querétaro en su lado sureste.

3. 2000 Fase de desurbanización: esta fase puede asociarse a la década del 2000 (véase en color verde Figura No.6), en la cual la conformación de la estructura se caracteriza por el crecimiento de sus núcleos urbanos y estos continúan expandiéndose a lo largo de su ubicación de referencia en 1970. Al respecto, cabe destacar la posición de las vías carreteras a partir de las cuales se distribuyen estos crecimientos urbanos de la ZM.

La distribución dispersa de la estructura territorial en su origen y los asentamientos periféricos dispersos obedecen a una estructura territorial ramificada similar a un racimo de uvas, que no liga a los asentamientos entre ellos. Esta distribución propicia la tendencia al aumento en la dispersión del crecimiento urbano y de la expansión urbana tan alejada de los contornos metropolitanos que se configuraron entre 1990 y 2000.

En esta estructura puede reconocerse la ubicación de El Pueblito y El Centro Sur. Al norte del corredor: La Cañada, Felipe Carrillo Puerto, El Cerrito, Jurica y Santa Rosa Jáuregui, los cuales conforman la característica de las nuevas centralidades de referencia en la jerarquía de la estructura territorial; a diferencia de otros núcleos urbanos que se observan desligados y sin integración como es el caso de Huimilpan y por otra parte, Chichimequillas y Amazcala ubicados dentro del municipio El Marqués.

4. 2010 Fase de reurbanización: esta fase puede relacionarse con el corte transversal 2010 (véase en color amarillo Figura No.6), debido a que entre el centro tradicional de la ZMQ y los puntos donde se asentaron los desarrollos industriales de las décadas de 1970 y 1980 , se generan nuevas urbanizaciones y expansiones como parte del proceso de metropolización; ya que se inician nuevos procesos de conurbación entre los núcleos urbanos de Santa Rosa Jáuregui y Jurica.

Del análisis en la estructura territorial en la escala metropolitana correspondiente, se puede observar un funcionamiento con tendencia hacia la polinuclearización, considerando la localización espacial de los núcleos urbanos ya señalados que iniciaron su proceso de crecimiento como localidades en la ZMQ (Vázquez, 2018: 282).

Finalmente, derivado de este acercamiento al fenómeno a través de la aplicación de las dos estructuras de análisis propuestas, se intenta dar respuesta a la pregunta de investigación y se obtienen los siguientes resultados de investigación. 


\section{RESULTADOS}

Las mediciones sobre el fenómeno urbano de proceso de metropolización se realizaron a partir de grupos de indicadores seleccionados para cada una de las categorías que se muestran en el esquema correspondiente al enfoque de Análisis Territorial (véase en Figura No.1 y Figura No.2). A continuación, se presentan los resultados obtenidos únicamente para la categoría urbana y en futuros trabajos se presentarán las siguientes categorías: ambiental, económica, política, social y cultural.

En una comparativa entre los datos obtenidos de los años 1990, 2000, 2010 se ha identificado que el crecimiento poblacional en la ZMQ se incrementó significativamente a partir de 1990 con 579,597 habitantes, resultando una densidad de 152.39 habitantes por $\mathrm{Ha}$; cuando en este momento de exploración la superficie de urbanización contaba con $3,803.50 \mathrm{Ha}$.

El año 2000 resalta con 816,481 habitantes, mientras su superficie urbanizada continúa expandiéndose y aumentando hasta llegar a 10,620.72 Ha; motivo por el cual, se observa en las gráficas (véase en Figura No. 3 y Figura No. 4) una disminución en la densidad con 76.88 habitantes por Ha.

En la siguiente década, la ZMQ resalta de manera desproporcionada respecto a los cortes transversales anteriores ya que se registran $1,097,025$ habitantes en 2010 , con $24,410.78 \mathrm{Ha}$ de superficie de urbanización; hecho que causa una baja densidad poblacional de 45.47 habitantes por hectárea de acuerdo a resultados de investigación (INEGI, 2010).

En otras palabras, durante el periodo de estudio la población no crece en proporción con la urbanización, pues sólo se eleva la cantidad de habitantes dos (2) veces en veinte (20) años.

En contraste (véase en Figura No.6) se observa que la superficie de urbanización en la ZMQ ha crecido de $1,041.89 \mathrm{Ha}$ en 1970 a 24,410.78 Ha en 2010 (INEGI, 2010); aumentando veinticuatro (24) veces su tamaño en cuarenta (40) años, por lo tanto esta relación toma relevancia en la investigación.
Figura 2. Categorías de análisis territorial aplicadas al proceso de metropolización de la ZMQ 1990-2010

\begin{tabular}{|c|c|}
\hline $\begin{array}{l}\text { CATEGORÍAS } \\
\text { ENFOQUE DE } \\
\text { ANÁLISIS } \\
\text { TERRITORIAL }\end{array}$ & $\begin{array}{c}\text { VARIABLES } \\
\text { E INDICADORES }\end{array}$ \\
\hline $\begin{array}{l}\text { Categoria } \\
\text { Urbana }\end{array}$ & $\begin{array}{l}\text { Crecimiento urbano disperso, } \\
\text { Precio bajo del suelo, Superfi- } \\
\text { cie de urbanización. }\end{array}$ \\
\hline $\begin{array}{l}\text { Categoria } \\
\text { Ambiental }\end{array}$ & $\begin{array}{l}\text { Zonas de protección ecológica } \\
\text { que se han urbanizado, Cali- } \\
\text { dad del aire, Contaminación } \\
\text { por ruido, Dotación de parques } \\
\text { urbanos. }\end{array}$ \\
\hline $\begin{array}{l}\text { Categoría } \\
\text { Económica }\end{array}$ & $\begin{array}{l}\text { Población económicamente } \\
\text { activa no agrícola, Valor agre- } \\
\text { gado en industrias de transfor- } \\
\text { mación. }\end{array}$ \\
\hline $\begin{array}{l}\text { Categoria } \\
\text { Social }\end{array}$ & $\begin{array}{l}\text { Atracción migratoria reciente, } \\
\text { Crecimiento poblacional, Tasa } \\
\text { de crecimiento medio anual de } \\
\text { la población, Densidad pobla- } \\
\text { cional, Estructura por edad y } \\
\text { sexo. }\end{array}$ \\
\hline $\begin{array}{l}\text { Categoria } \\
\text { Politica }\end{array}$ & $\begin{array}{l}\text { Obras en las que se aplicó el } \\
\text { fondo metropolitano. }\end{array}$ \\
\hline $\begin{array}{l}\text { Categoria } \\
\text { Cultural }\end{array}$ & $\begin{array}{l}\text { Sentido de pertenencia ligado } \\
\text { al lugar de origen. }\end{array}$ \\
\hline $\begin{array}{l}\text { Subsistema } \\
\text { Demográfico }\end{array}$ & $\begin{array}{l}\text { Inmigración, edad, sexo, es- } \\
\text { tructura familiar, defunciones, } \\
\text { nacimientos. }\end{array}$ \\
\hline $\begin{array}{l}\text { Subsistema } \\
\text { Económico }\end{array}$ & $\begin{array}{l}\text { Actividad económica de la po- } \\
\text { blación, ingreso, actividad eco- } \\
\text { nómica por sector y zona. }\end{array}$ \\
\hline $\begin{array}{l}\text { Subsistema } \\
\text { Uso de Suelo }\end{array}$ & $\begin{array}{l}\text { Capacidad y precio del suelo, } \\
\text { cantidad de suelo utilizado, } \\
\text { suelo industrial, residencial, } \\
\text { viario, comercial. }\end{array}$ \\
\hline $\begin{array}{l}\text { Subsistema } \\
\text { Residencia - } \\
\text { empleo }\end{array}$ & $\begin{array}{l}\text { Distancia entre la vivienda y el } \\
\text { empleo, Costo de traslados, } \\
\text { Demanda y oferta de vivienda } \\
\text { por zona de residencia, vivien- } \\
\text { das vacantes, demanda y ofer- } \\
\text { ta de empleo por zona. }\end{array}$ \\
\hline $\begin{array}{l}\text { Subsistema de } \\
\text { Servicios }\end{array}$ & $\begin{array}{l}\text { Distancia entre núcleos de ser- } \\
\text { vicios, Demanda y utilización } \\
\text { de los servicios por zona. }\end{array}$ \\
\hline $\begin{array}{l}\text { Subsistema } \\
\text { Medios de } \\
\text { transporte }\end{array}$ & $\begin{array}{l}\text { Tiempos y distancias, Deman- } \\
\text { da, oferta y utilización del } \\
\text { transporte, costos, posesión } \\
\text { de automóvil. }\end{array}$ \\
\hline
\end{tabular}

Fuente: Elaboración propia con base en (Vázquez, 2018). 
Figura 3. Tabla el proceso de metropolización en la ZMQ 1990-2010

\begin{tabular}{|c|c|c|c|c|c|c|}
\hline & $\begin{array}{c}\text { PEA en } \\
\text { Queretaro }\end{array}$ & $\begin{array}{c}\text { Población } \\
\text { nacida en } \\
\text { Querétaro }\end{array}$ & $\begin{array}{c}\text { Población } \\
\text { nacida en otra } \\
\text { entidad } \\
\text { federativa }\end{array}$ & $\begin{array}{c}\text { PEA en } \\
\text { Huimilpan }\end{array}$ & $\begin{array}{c}\text { Población } \\
\text { nacida en } \\
\text { Querétaro }\end{array}$ & $\begin{array}{c}\text { Población } \\
\text { nacida } \\
\text { en otra } \\
\text { entidad } \\
\text { federativa }\end{array}$ \\
\hline & QUERÉTARO & QUERÉTARO & QUERÉTARO & HUIMILPAN & HUIMILPAN & HUIMILPAN \\
\hline 1990 & 143,819 & $/$ & $/$ & 5,680 & $/$ & $/$ \\
\hline 2000 & 251,863 & 438,383 & 194,696 & 5,578 & 28,014 & 703 \\
\hline 2010 & 362,595 & 535,739 & 249,457 & 11,883 & 33,436 & 1,801 \\
\hline
\end{tabular}

\begin{tabular}{|c|c|c|c|c|c|c|}
\hline & $\begin{array}{c}\text { PEA en } \\
\text { Corregidora }\end{array}$ & $\begin{array}{c}\text { Población } \\
\text { nacida en } \\
\text { Querétaro }\end{array}$ & $\begin{array}{c}\text { Población } \\
\text { nacida en otra } \\
\text { entidad } \\
\text { federativa }\end{array}$ & $\begin{array}{c}\text { PEA en EI } \\
\text { Marqués }\end{array}$ & $\begin{array}{c}\text { Población } \\
\text { nacida en } \\
\text { Querétaro }\end{array}$ & $\begin{array}{c}\text { Población } \\
\text { nacida } \\
\text { en otra } \\
\text { entidad } \\
\text { federativa }\end{array}$ \\
\hline & CORREGIDORA & CORREGIDORA & CORREGIDORA & $\begin{array}{c}\text { EL } \\
\text { MARQUÉS }\end{array}$ & EL MARQUÉS & EL MARQUÉS \\
\hline 1990 & 12,122 & $/$ & $/$ & 14,110 & $/$ & $/$ \\
\hline 2000 & 27,151 & 53,725 & 19,855 & 22,246 & 68,193 & 2,654 \\
\hline 2010 & 63,790 & 86,879 & 53,292 & 46,311 & 102,312 & 12,883 \\
\hline
\end{tabular}

\begin{tabular}{|c|c|c|c|c|c|c|}
\hline & $\begin{array}{c}\text { Población } \\
\text { total en } \\
\text { Querétaro }\end{array}$ & $\begin{array}{c}\text { Población } \\
\text { total en } \\
\text { Huimilpan }\end{array}$ & $\begin{array}{c}\text { Población } \\
\text { total en } \\
\text { Corregidora }\end{array}$ & $\begin{array}{c}\text { Población } \\
\text { total en EI } \\
\text { Marqués }\end{array}$ & $\begin{array}{c}\text { Población } \\
\text { Total en } \\
\text { Zona } \\
\text { Metropolitana }\end{array}$ & $\begin{array}{c}\text { PEA Total en } \\
\text { la Zona } \\
\text { Metropolitana }\end{array}$ \\
\hline 1990 & 456,458 & 24,106 & 43,775 & 55,258 & 579,597 & 175,731 \\
\hline 2000 & 641,386 & 29,140 & 74,558 & 71,397 & 816,481 & 306,838 \\
\hline 2010 & 801,940 & 35,554 & 143,073 & 116,458 & $1,097,025$ & 484,579 \\
\hline
\end{tabular}

\begin{tabular}{|c|c|c|c|c|c|c|}
\hline & $\begin{array}{c}\text { Población } \\
\text { Total en Zona } \\
\text { Metropolitana }\end{array}$ & $\begin{array}{c}\text { Superficie } \\
\text { Urbanizada en } \\
\text { Hectáreas Ha }\end{array}$ & $\begin{array}{c}\text { Habitantes por } \\
\text { Hectárea en } \\
\text { ZMQ }\end{array}$ & $\begin{array}{c}\text { Inmigración } \\
\text { interestatal }\end{array}$ & $\begin{array}{c}\text { Población } \\
\text { nacida en } \\
\text { Querétaro }\end{array}$ & $\begin{array}{c}\text { Población } \\
\text { nacida en } \\
\text { otra entidad } \\
\text { federativa }\end{array}$ \\
\hline & PTOTAL ZMQ & SUP URB ZMQ & HAB POR HA & INMIG ZMQ & TOTAL ZMQ & TOTAL ZMQ \\
\hline 1990 & 579,597 & $3,803.50$ & 152.39 & 5,420 & $/$ & $/$ \\
\hline 2000 & 816,481 & $10,620.72$ & 76.88 & 8,031 & 588,315 & 217,908 \\
\hline 2010 & $1,097,025$ & $24,125.02$ & 45.47 & 9,567 & 758,366 & 317,433 \\
\hline
\end{tabular}


Figura 4. Gráficas sobre el proceso de metropolización en la ZMQ 1990-2010

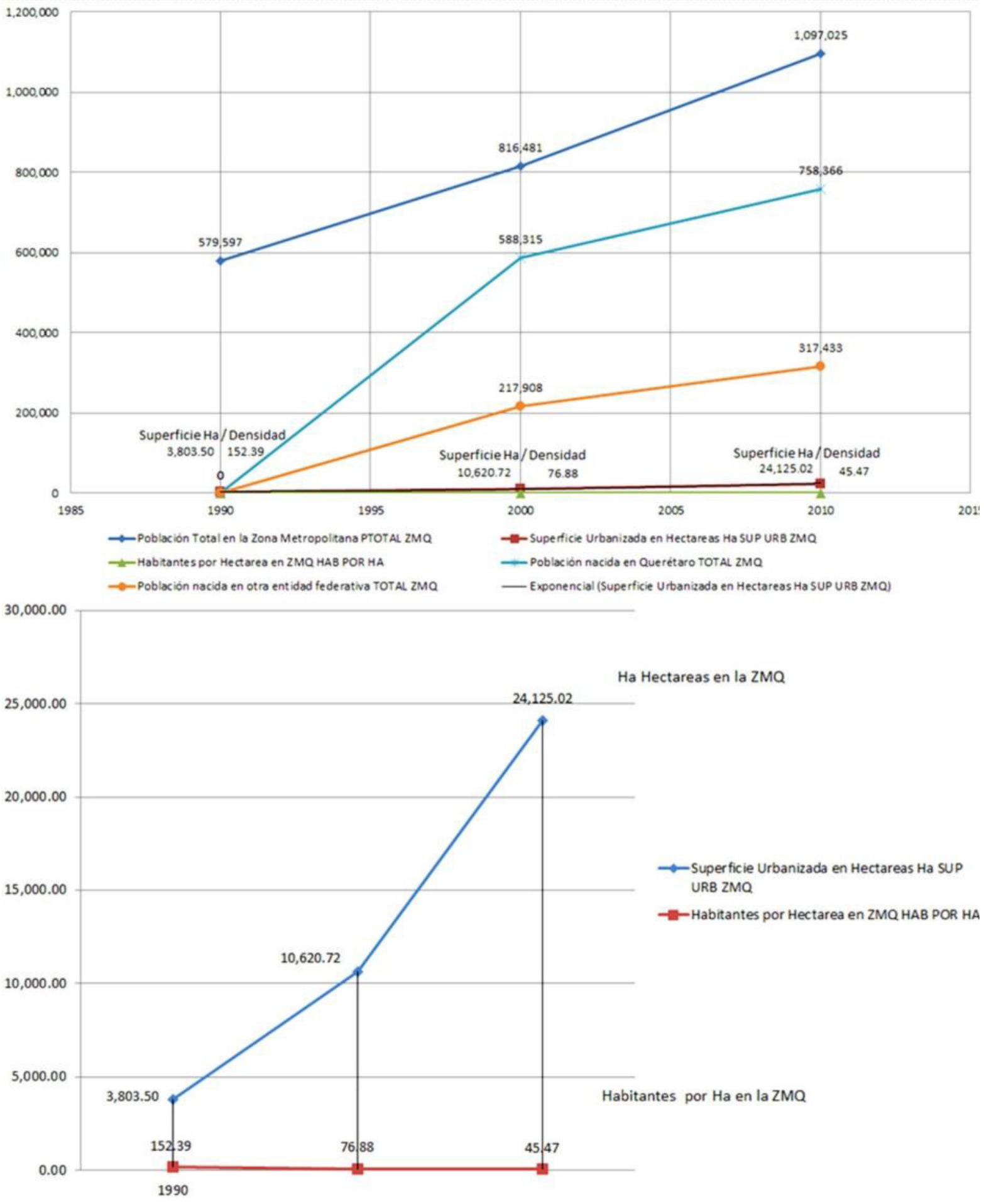

Fuente: Elaboración propia con base en (Vázquez, 2018). 
Los resultados obtenidos al aplicar el enfoque del Análisis Territorial han permitido observar que determinadas características como la densidad y la inmigración interestatal pueden explicar en gran parte la ocupación del suelo a través del tiempo y el proceso de metropolización, por lo tanto, se han relacionado las características del territorio con la distribución de la tendencia en el crecimiento urbano. Las variables más significativas que aportan una clara tendencia en correlación con el proceso de metropolización son: la inmigración interestatal, el crecimiento urbano disperso, el bajo precio del suelo y la población total.

La investigación ha requerido de dos cortes temporales transversales de los años 1970 y 1980, para lograr una comparativa más significativa en términos de observar el crecimiento urbano en la parte gráfica y por otra parte, con el objeto de tomar dos puntos de referencia para realizar el análisis de correlación de datos e interpretación de los resultados de investigación (véase en Figuras No. 7 y No. 8).

Con base en la técnica de correlación lineal y aplicando la fórmula de Correlación de Karl Pearson, para obtener el producto $x$ en un momento $y$ para calcular de esta manera los efectos del proceso de metropolización en la ZMQ. En este sentido, se correlacionan los valores de coberturas en la superficie de urbanización para los momentos correspondientes al periodo de estudio 1990-2010, con los datos sociodemográficos obtenidos de la colecta.
Figura 5. Crecimiento urbano disperso y bajo precio de suelo en la ZMQ 1990-2010

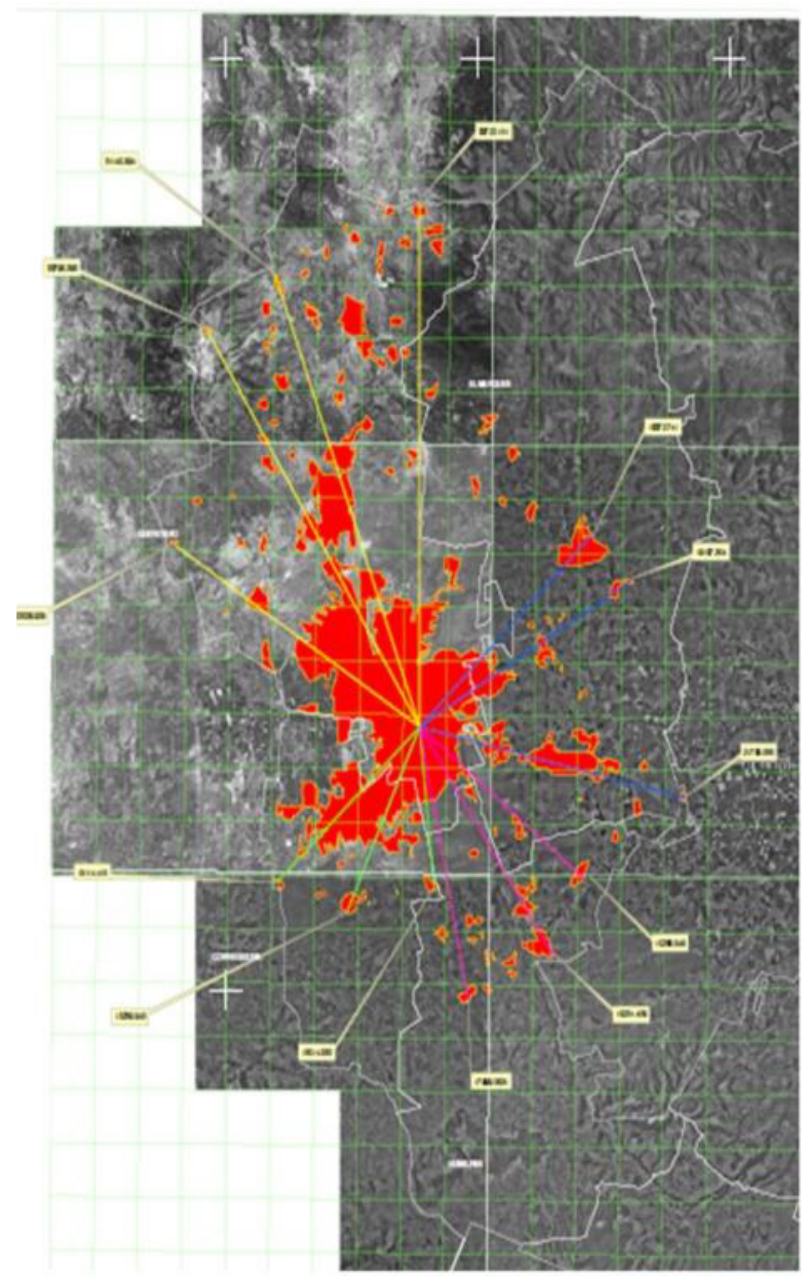

\begin{tabular}{|c|c|}
\hline $\begin{array}{c}\text { Distancia Lineal del Centro Histórico } \\
\text { a Poligonos de la muestra }\end{array}$ & $\begin{array}{c}\text { Municipios de la Zona Metropolitana } \\
\text { de Querétaro }\end{array}$ \\
\hline 16288.848 & Poligono 1. Huimilpan \\
\hline 17999.0831 & Poligono 2. Huimilpan \\
\hline 18251.409 & Poligono 3. Huimilpan \\
\hline 10614.330 & Poligono 1. Corregidora \\
\hline 13239.943 & Poligono 2. Corregidora \\
\hline 15114.415 & Poligono 3. Corregidora \\
\hline 18372.741 & Poligono 1. El Marques \\
\hline 19187.304 & Poligono 2. El Marques \\
\hline 21708.000 & Poligono 3. El Marques \\
\hline 22638.935 & Poligono 1. Querétaro \\
\hline 30798.390 & Poligono 2. Querétaro \\
\hline 31146.894 & Poligono 3. Querétaro \\
\hline 33722.151 & Poligono 4. Querétaro \\
\hline
\end{tabular}


Figura 6. Secuencia de crecimiento en la estructura territorial de la Zona Metropolitana de Querétaro 1990-2010.
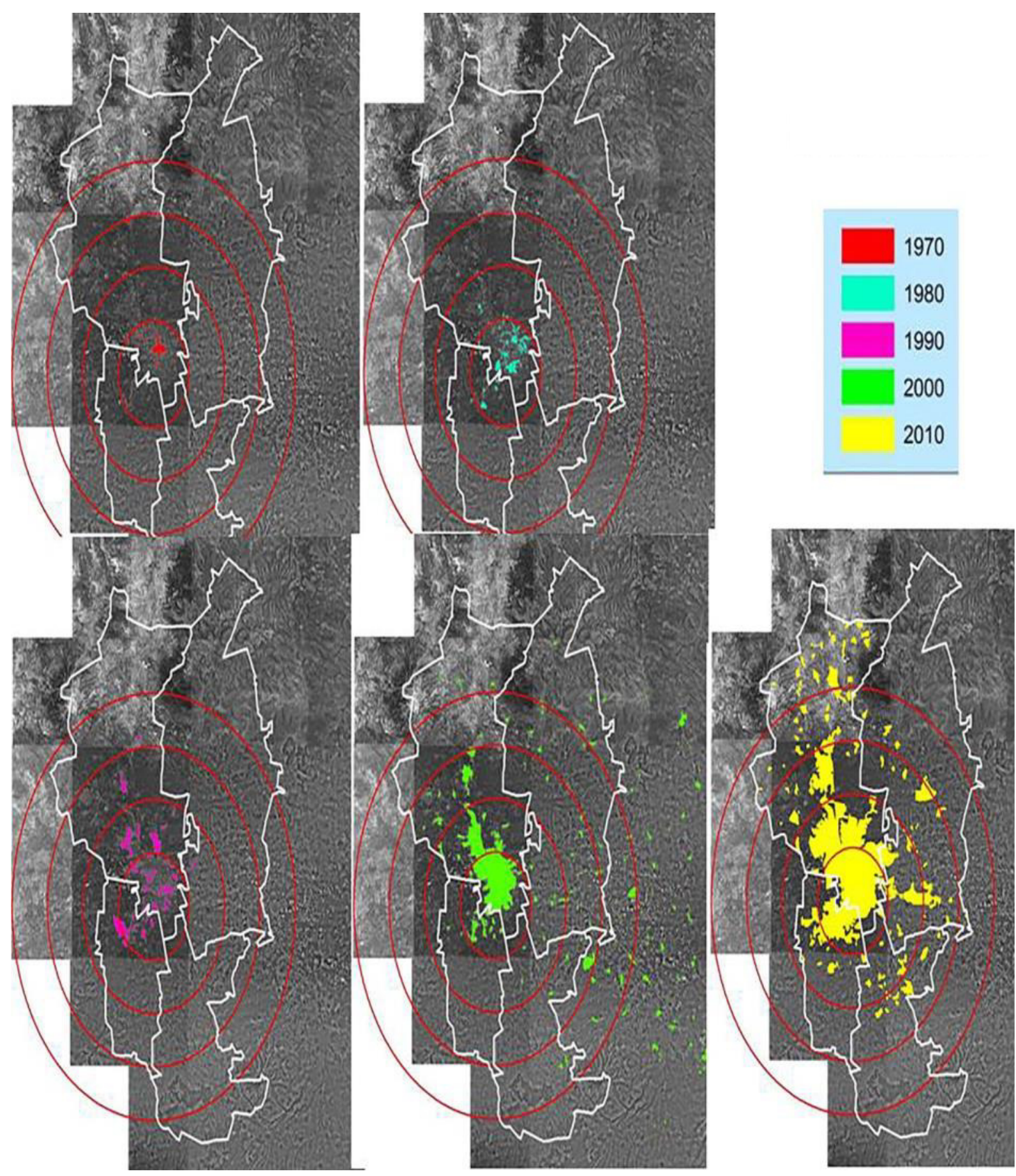

Fuente: Elaboración propia con base en (Vázquez, 2018). 
Figura 7. Correlaciones resultado de investigación
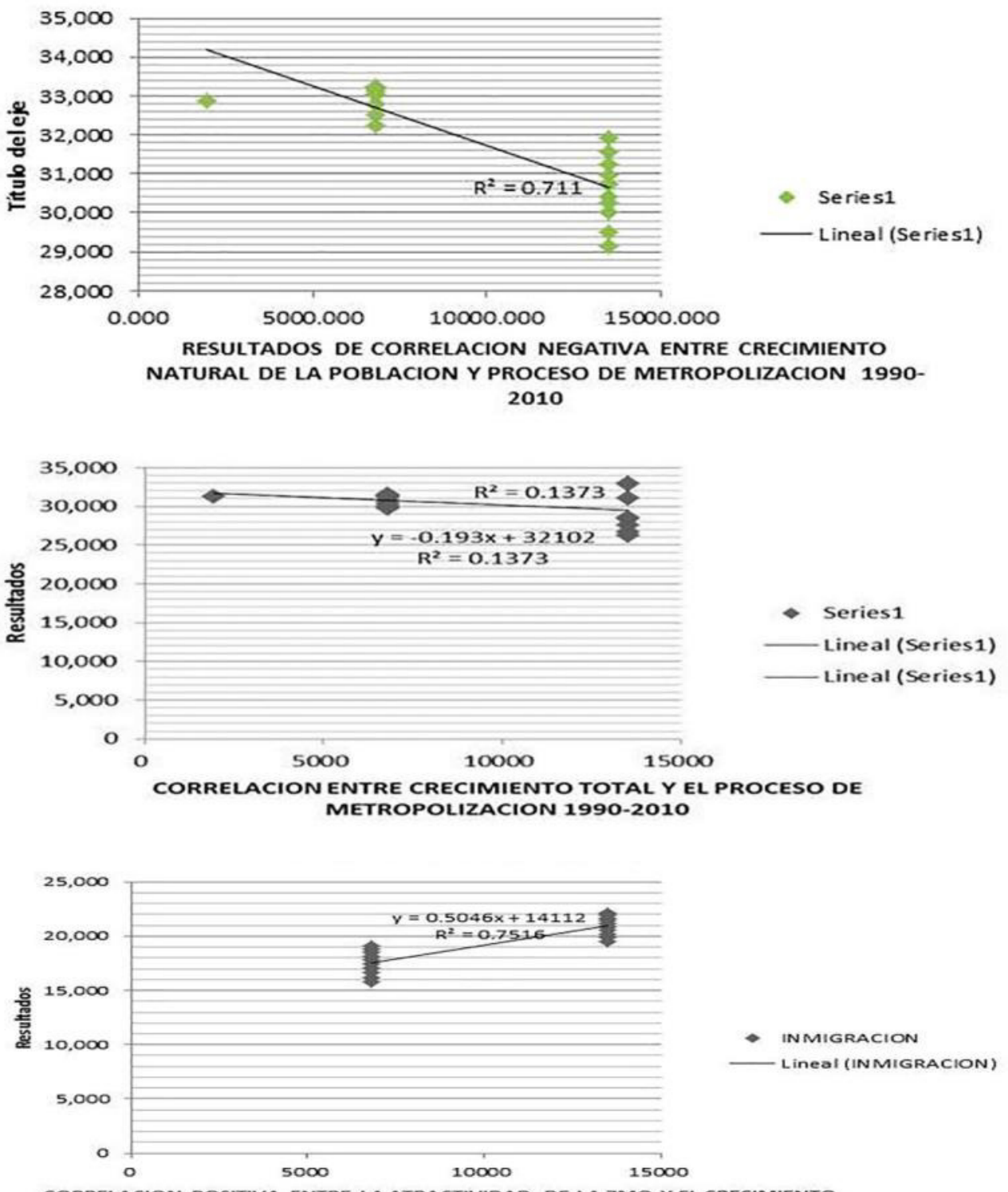

CORRELACION POSITIVA ENTRE LAATRACTIVIDAD DE LA ZMQ Y EL CRECIMIENTO DE LA SUPERFICIE DE URBANIZACION 1990-2010

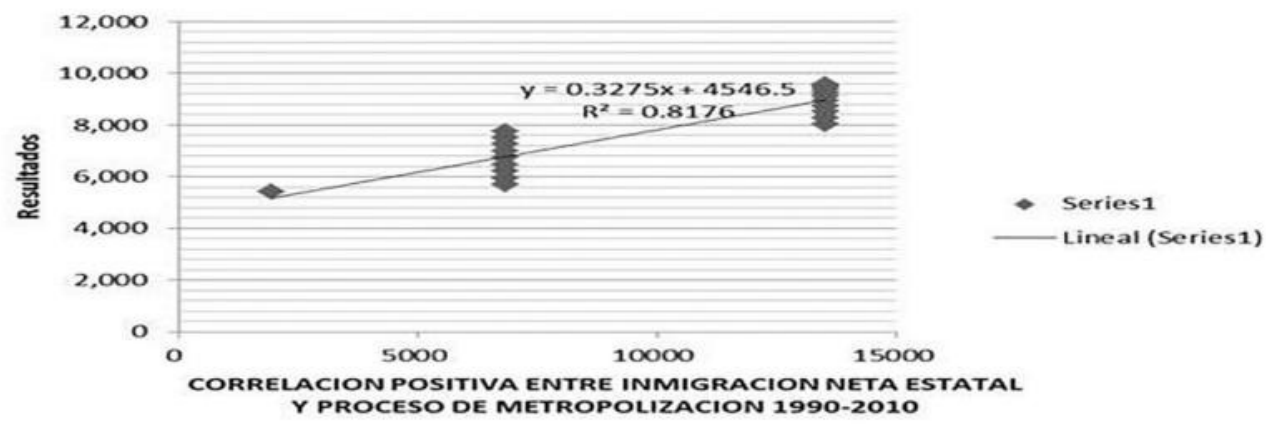

Fuente: Elaboración propia con base en (Vázquez, 2018). 
Figura 8. Mapa resultante el proceso de metropolización en Querétaro
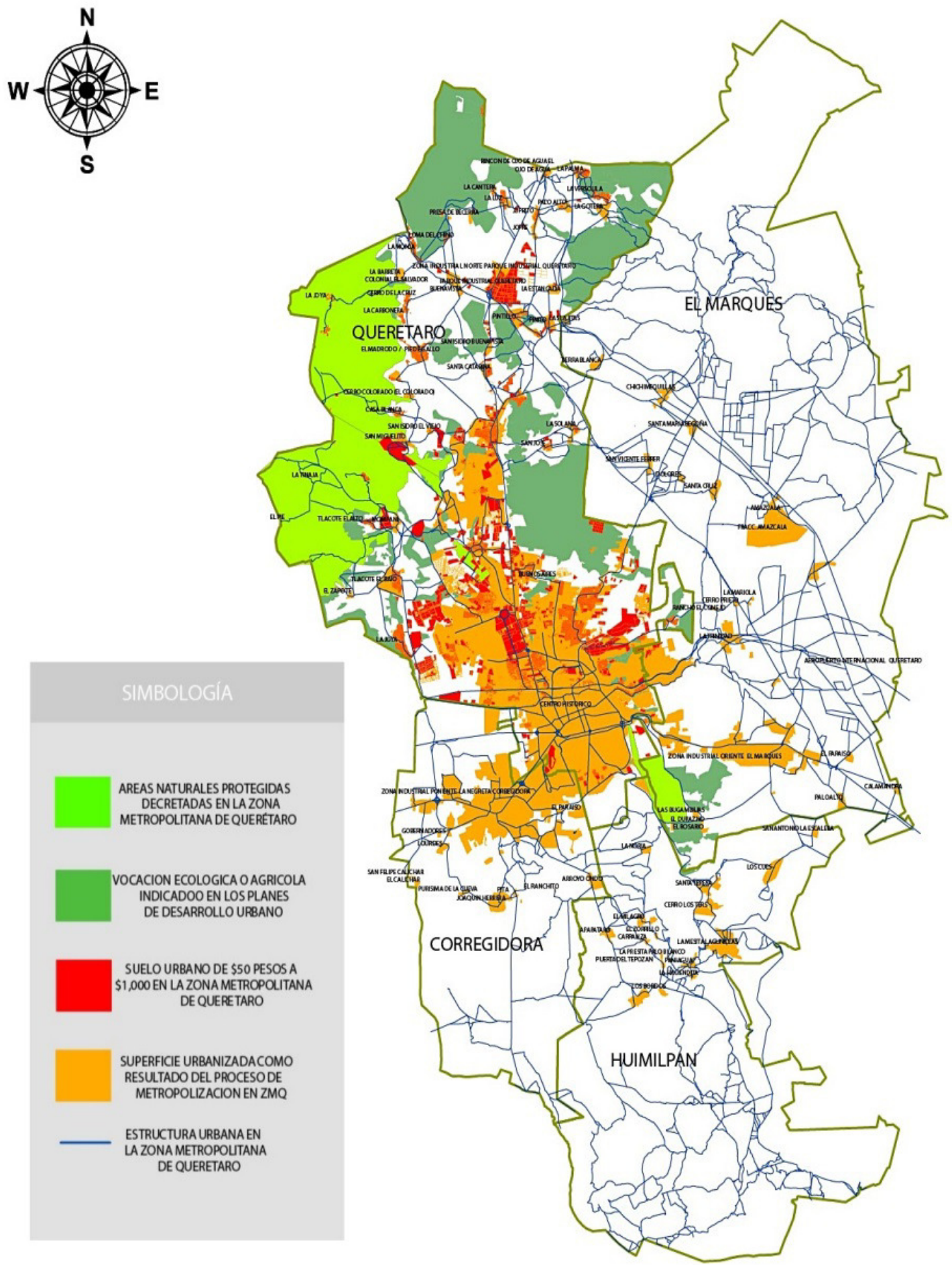

Fuente: Elaboración propia con base en (Vázquez, 2018). 


\section{CONCLUSIONES.}

Primero, en base al análisis e interpretación de las correlaciones, es posible afirmar que en el caso del fenómeno urbano del proceso de metropolización en la ZMQ, el crecimiento natural de la población no es una causal del fenómeno, por lo tanto no aporta relevancia como indicador explicativo. Se comprueba la correlación positiva entre la inmigración y el proceso de metropolización como el factor de mayor impacto en la ZMQ entre 19902010. Lo cual coincide con los argumentos que plantea Unikel (1976) respecto a los indicadores del proceso de metropolización.

Segundo, en la ZMQ se identifica que el proceso de metropolización se comporta en correspondencia con el modelo explicativo de Sousa (2010), sobre la generatriz de contornos metropolitanos. Se puede deducir que el proceso de metropolización constituye un fenómeno multifactorial, mayormente asociado a las fluctuaciones de inmigración. Su manifestación física en el territorio es evidente a través de los mapas de resultados, en los cuales se observa la estructura territorial de tipo polinuclear en conjunto con el modelo de crecimiento urbano disperso y la secuencia de expansiones en la superficie de urbanización, que se modifica entre cada década 1990, 2000 y 2010.

Tercero, los mapas de resultados permiten observar comparativamente el suelo urbano de bajo precio que se localiza en zonas alejadas y desligadas de la estructura territorial en donde se ha desarrollado vivienda, servicios e industria, en coincidencia con la Teoría de la Subasta del Suelo Urbano. Por lo anterior, se verifica que el bajo costo del suelo en su relación con la distancia respecto a un centro metropolitano, tiene implicaciones directas en la tendencia de la urbanización dispersa e insustentable en la escala de nivel metropolitano y sobre el proceso de metropolización en la ZMQ. Se comprueba la hipótesis, ya que el proceso de metropolización en la ZMQ se comporta de acuerdo a la Teoría de la Subasta del Suelo Urbano y se verifica la inmigración como consumidor de la nueva oferta de suelo urbano.

Cuarto, como parte de los resultados obtenidos, se comprueba una influencia del terremoto de 1985 en la llegada masiva de habitantes del Distrito Federal hacia la ciudad de Querétaro, por lo cual, será importante retomar el estudio a partir del reciente terremoto de la Ciudad de México en
2017, para estudiar su impacto en la inmigración y en el proceso de metropolización de la ZMQ en las próximas décadas 2030-2050.

Quinto, queda para futuras investigaciones, la aplicación de correlaciones múltiples ampliando a grupos de variables, para avanzar en el conocimiento sobre el fenómeno. Los recientes avances tanto teóricos como aplicados desde el enfoque de Análisis Territorial, facilitan a los investigadores una nueva visión del proceso de metropolización que puede complementar y enriquecer los enfoques de corte cuantitativo.

Sexto, en la búsqueda de posibles propuestas de solución, se considera que puede ser de utilidad la implementación de un cinturón verde en conjunto con un sistema de parques urbanos para la ZMQ, ambos como elementos de contención de la urbanización dispersa y sin regulación que se presenta actualmente.

\section{BIBLIOGRAFÍA}

Bassols, Mario (2006), Explorando el régimen urbano en México: Un análisis metropolitano, México, UAM.

Chorley, Richard y Peter Haggett (1971), La Geografía y los Modelos Socioeconómicos, Madrid, Methuen \& Co. Ltd.

Consejo Nacional de Población (2004), Delimitación de las Zonas Metropolitanas de México, México, 169 p. CONAPO.

(2010),

Delimitación de las Zonas Metropolitanas de México 2010, México, CONAPOINEGI SEDESOL.

(2012),

Proyecciones de la Población de las Zonas Metropolitanas 2010-2030, México, CONAPO-INEGI-SEDESOL.

Delgado, Javier (1993), "Querétaro: hacia una ciudad región", en Revista Estudios Demográficos y Urbanos, Vol. 8, núm. 3, septiembre-diciembre, pp. 655-699.

Duhau, Emilio (1988), Planeación metropolitana y política urbana municipal en la ciudad de México, México, UAM.

Eibenschutz, Roberto y Goya Comps. (2009a), Estudio de la Integración Urbana y Social en la Expansión Reciente de las Ciudades en México,1996-2006:dimensión, características y soluciones, México, Universidad Autónoma Metropolitana. 
Eibenschutz, Roberto y Pablo Benlliure (2009b), Mercado formal e informal del suelo. Análisis de ocho ciudades, México, Cámara de Diputados / Sedesol / UAM-X / Miguel Ángel Porrúa

Flores, Sergio (1993), Desarrollo Metropolitano. Análisis y Perspectivas, México, Benemérita Universidad Autónoma de Puebla.

Garrocho, Carlos y Jaime Sobrino (1995), Sistemas Metropolitanos: Nuevos enfoques y prospectiva, México, El Colegio de México.

Garza, Gustavo et al. (1999), Políticas urbanas en grandes metrópolis: Detroit, Monterrey y Toronto, México, El Colegio de México.

Hall, Peter et al. (1975), Modelos de Análisis Territorial, Barcelona, Oikos-tau.

Hagget, Peter (1979), Geography a Modern Synthesis, New York, Harper International.

Harris, Britton et al. (1975), Modelos de Desarrollo Urbano, Barcelona, Oikos-tau.

Hernández, Luis y Ojeda Fátima (2019), "Cuantificación y caracterización de polen atmosférico en el norte de la ciudad de Santiago de Querétaro, Qro.”, en Revista Nthe, núm. 31, septiembre-diciembre,2019, pp. 1-6.

Icazuriaga, Carmen (1992), La metropolización de la Ciudad de México a través de la instalación industrial, México, Centro de Investigaciones y Estudios superiores de Antropología Social.

Indovina, Francesco (2007), La ciudad de baja densidad. Lógicas, gestión y contención, Barcelona, Diputación de Barcelona.

Iracheta, Alfonso (1988), "Metropolización y política urbana en la ciudad de México: en busca de un Nuevo enfoque", en Revista Estudios Demográficos y Urbanos, Vol. 3 núm. 1, enero, pp. 143-162.

(2009), Políticas públicas

para gobernar las metrópolis mexicanas, México, El Colegio Mexiquense.

(2012), Metrópolis en crisis: una propuesta para la zona metropolitana Puebla-Tlaxcala, México, Universidad Autónoma de Puebla.

Isard, Walter (1960), Métodos de Análisis Regional, Barcelona, Ariel.

Johnson, James (1987), Geografía urbana, España, Oikos-tau.
Negrete, Eugenia y Héctor Salazar (1986), "Zonas metropolitanas en México, 1980", en Revista Estudios Demográficos y Urbanos, Vol. 1, núm. 1, enero, pp. 97-124.

Negrete, Eugenia (2010), Las metrópolis mexicanas: conceptualización, gestión y agenda de políticas", en Los Grandes Problemas de México, Vol. II Desarrollo urbano y regional, México, El Colegio de México.

Nolasco, Margarita (1981a), Cuatro ciudades. El proceso de urbanización dependiente, México, INAH.

Nolasco, Margarita (1981b), Políticas de desarrollo metropolitano en la Ciudad de México, México, Cepal.

Pujadas, Roma (1998), Ordenación y Planificación Territorial, Madrid, Síntesis.

Salazar, Héctor (1984), Dinámica del crecimiento de las ciudades intermedias en México: Los casos de León, San Luis Potosí y Torreón (1970-1980),México, El Colegio de México.

Secchi, Bernardo (1968), Análisis de las Estructuras Territoriales, Barcelona, Gustavo Gili.

Sobrino, Jaime (2010), "Ciclos económicos y competitividad de las ciudades", en Gustavo Garza y Martha Schteingart (coords.), Los grandes problemas de México. Desarrollo urbano y regional, México, El Colegio de México, pp. 127171.

Sousa, Eduardo (2006), El Área Metropolitana de Monterrey: Análisis y propuesta de lineamientos metodológicos para la planeación en zonas periféricas, Tesis de Doctorado en Filosofía con Orientación en Arquitectura y Estudios Urbanos, México, Universidad Autónoma de Nuevo León. (2010), "De la ciudad a la metrópoli. Una interpretación teórica del fenómeno expansivo ligado a la vivienda, a la vulnerabilidad y a la pobreza: el caso del área Metropolitana de Monterrey”, en Revista INVI, Vol. 25 núm. 69, agosto, pp. 19-101.

(2012), "De la ciudad a la metrópolis prematura: Los tres Procesos", en Revista Urbano, Vol. 15, núm. 26, noviembre, 2012, pp. 54-64.

Stuart, Chapin (1977), Planificación del Uso de Suelo Urbano, Barcelona, Oikos-tau. 
Tapia, Jorge (2009), Cambio socio territorial en el contexto de las metrópolis, en Dinámicas Ambientales y Territoriales en México. Una disciplina multidisciplinaria, México, Universidad Autónoma del Estado de México.

Tovar, Edgar (2010), "Génesis del proceso de Metropolización en Guadalajara", en Revista Territorios Metropolitanos Artículos y ensayos de investigación, Vol. 03, núm. 03-04, junio-diciembre, pp. 5-18.

Un-hábitat (1976), Declaración de Vancouver sobre los Asentamientos Humanos, Canadá, Naciones Unidas.

(2011), Estado de las Ciudades de México, México, Programa de las Naciones Unidas para los Asentamientos Humanos.

(2012), State of World's Cities 2012/2013, Programa de las Naciones Unidas para los Asentamientos Humanos, Estados Unidos Canadá, Routledge.

Unikel, Luis (1960), Ensayo para la delimitación de la zona metropolitana de la Ciudad de México en 1940, 1950 y 1960, México, El Colegio de México.

Unikel, Luis et al. (1976), El Desarrollo urbano de México: Diagnóstico e implicaciones futuras, México, El Colegio de México.

Vargas, Pablo (2011), "La conflictividad en el Proceso de Metropolización de Pachuca", en Revista Papeles de Población, Vol. 17, núm. 68, abril-junio, 2011, pp. 127-146.

Vázquez Cruz, Rubí del Rocío (2011), Propuesta Metodológica para la formulación de un Modelo de Ordenamiento Territorial, Tesis de Maestría en Planeamiento Urbano y Regional, México, Universidad de Guanajuato.

Vázquez Cruz, Rubí del Rocío (2018), El Proceso de Metropolización. Querétaro:1990-2010, Tesis de Doctorado en Arquitectura, México, Universidad de Guanajuato. https://orcid.org/0000-0003-0451-7798

Wilson, A.G. (1980), Geografía y Planeamiento Urbano y Regional, Madrid, Oikos-tau. 